University of Texas Rio Grande Valley

ScholarWorks @ UTRGV

\title{
Investigating Educators' Views of Sexuality, HIV and AIDS Education in Working with Students with Disabilities in South African Schools
}

\author{
Julia S. Louw \\ John Kosciulek \\ Roy K. Chen \\ The University of Texas Rio Grande Valley
}

Follow this and additional works at: https://scholarworks.utrgv.edu/rhc_fac

Part of the Disability Studies Commons, and the Rehabilitation and Therapy Commons

\section{Recommended Citation}

Louw, Julia S., John Kosciulek, and Roy K. Chen. 2014. "Investigating Educators' Views of Sexuality, HIV and AIDS Education in Working with Students with Disabilities in South African Schools." Journal of Applied Rehabilitation Counseling 45 (2): 9-17. https://doi.org/10.1891/0047-2220.45.2.9.

This Article is brought to you for free and open access by the College of Health Professions at ScholarWorks @ UTRGV. It has been accepted for inclusion in School of Rehabilitation Services \& Counseling Faculty Publications and Presentations by an authorized administrator of ScholarWorks @ UTRGV. For more information, please contact justin.white@utrgv.edu,william.flores01@utrgv.edu. 


\title{
Investigating Educators' Views of Sexuality, HIV and AIDS Education in Working with Students with Disabilities in South African Schools
}

\author{
Julia S. Louw \\ John Kosciulek \\ Roy K. Chen
}

\begin{tabular}{l} 
Abstract-- The misconception that persons with disabilities are asexual and sexually inactive \\
often relegates teaching sexuality education in special needs schools to a priority of low im- \\
portance. The access, or lack thereof, to such information causes students with disabilities to \\
be at an increased risk of HIV infection, therefore, providing them with sexuality education is \\
imperative. The purpose of the present study was to examine the teachers' and childcare pro- \\
viders'views of teaching sexuality, HIV, and AIDS programs in special needs schools. A sur- \\
vey questionnaire was employed to collect the data. The results showed that among the four \\
major study constructs, teaching practices had the highest mean scores $(M=4.2)$. A correla- \\
tion matrix among the 10 study variables indicates the strongest positive associations for \\
teaching practices with cure for HIV $(r=.37, p<.01)$ and the seriousness of the AIDS prob- \\
lem $(r=.35, p<.05)$ with programs related to HIV and AIDS. The study confirmed the teach- \\
ers' high levels of knowledge regarding HIV and AIDS and that they were taking the teaching \\
of sexuality education to students with disabilities seriously. The teachers, however, ques- \\
tioned who should be held responsible for teaching this sexulity education, which may have \\
an impact on their attitudes and beliefs as well as their teaching practices of the topic. \\
Keywords: South Africa, students with disabilities, sexuality education, HIV and AIDS \\
\hline
\end{tabular}

$\mathrm{T}$ he prevalence of persons living with HIV globally has stabilized since 2000 , but AIDS continues to cause immense human suffering worldwide (UNAIDS, 2008). The impact of the disease has been especially huge on vulnerable populations and marginalized groups such as persons with disabilities (Chappell \& Radebe, 2009; Groce, 2005). There appears to be a faulty assumption that persons with disabilities are not at a high risk of HIV infection because they are often perceived as asexual and sexually inactive (UNICEF, 2013; World Bank, 2004). On the contrary, individuals with mental, physical, sensory or intellectual disabilities are perhaps more susceptible to every known risk factor for HIV and AIDS infection (Groce, 2003). Furthermore, persons with disabilities are more likely than others to be poor, among the most stigmatized, inadequately educated about sex, and vulnerable to sexual abuse (Kaiser Family Foundation, 2007; World Bank, 2004). In fact, behavioral risk factors for HIV associated with sexual activity among persons with disabilities are the same as those for the general population (Groce, 2005).

Particularly in sub-Saharan Africa, the HIV and AIDS epidemic has had its most profound impact to date (Mpofu et al., 2007; UNAIDS, 2008). It is reported that nearly $90 \%$ of all HIV positive children reside in sub-Saharan Africa where an estimated $67 \%$ of all people are living with HIV (UNAIDS, 2008). According to the Statistics South Africa (2013), there are more than five million people living with HIV in South Africa alone, by far the greatest number of any country in the world. Women comprise the majority of those living with HIV and AIDS in the region and young people are at a particularly high risk (Kaiser Family Foundation, 2007; UNAIDS, 2008). Persons with disabilities are largely ignored in HIV prevention campaigns worldwide (Groce, 2003). Various reasons have been advanced for the lack of attention to HIV prevention 
issues for persons with disabilities. These include the lack of appropriate educational material and insufficient training of teachers and health professionals working with person with disabilities (Wazakili, Mpofu, \& Devlieger, 2009). Moreover, the risk factors related to HIV transmission for adolescents are compounded by social marginalization from the rest of society (World Bank, 2008). Teens with disabilities are frequently "excluded from social interaction thus limiting their opportunities to set boundaries for themselves" when they engage with the opposite sex (Groce, 2005 , p. 217). As a result, teens with disabilities are most often pressured into sex because of their desperate need for acceptance and inclusion (Wazakali et al., 2009).

Providing information about HIV and AIDS to youth with disabilities is complicated (Chappell \& Radebe, 2009; Cheng \& Udry, 2002; Groce, Yousafzai, Dlamini, \& Wirz, 2006; Mulindwa, 2003; Wazakili et al., 2009). In Africa in particular, high illiteracy rates are a factor and even when AIDS education is available youth with disabilities may be often excused from such instruction because teachers may assume that they will not need the information (Chappell \& Radebe, 2009). Disability issues in South Africa are officially addressed at the national level through the Office on the Status of Disabled Persons (OSDP) as designated by the head of the state, President and a White Paper on an Integrated National Disability Strategy (INDS), which is a progressive step. But, according to the Department of Education of South Africa (2004), a large proportion of youth with disabilities are not in formal school. Furthermore, Schneider (2000) reports that many youth with disabilities under the age of 18 only reach primary level education and they are less likely to reach 12 th grade. Chappell and Radebe (2009) further emphasize the critical role education plays in the development of skills, knowledge, and identity; therefore without proper education, youth with disabilities are unable to participate in the social and economic activities of mainstream society.

Teachers can play an integral role in formal programs of sexuality education. They are often the only people discussing sexuality with young people. The importance of educators in sexuality education has long been noted (Greenberg, 1989; Schultz \& Boyd, 1984). McCary (1982) argues that "of all the arguments against school sex education, perhaps the most valid concern is the qualifications of those who teach it (p.17)." According to Thomas, Long, Whitten, Hamilton, Fraser, \& Askins, 1985, sexuality education can only result in long-term knowledge for students if taught by well-trained and experienced sexuality educators. Effectively addressing the need in updated relevant sexuality and HIV and AIDS programs may prevent any negative attitudes to interfere with their abilities to teach sexuality education (Yarber \& McCabe, 1984). These programs would need to include updated information on the development of the HIV epidemic in the SA context, sexual behaviour and HIV risk factors but more importantly, a renewed focus on promoting healthy behaviour as well as tailored strategies that apply specifically to dealing with children with different types of disabilities and how to best communicate this important information to them.

School is indisputably one of the most important learning environments because it is there that children and youth encounter the most extensive opportunities to socialize with their peers (NICHCY, 1992). Therefore, both parents and the school system should take responsibility for teaching children and youth about appropriate behaviors, social skills, and the development of sexuality (NICHCY, 1992). In addition, teachers and childcare providers must consider the point in life at which their students' disabilities occurred and the subsequent effects the disabilities may have had on their psychosocial development. In particular, youth with disabilities need additional attention and guidance because they tend to first internalize that they are disabled before learning to see themselves as sexual people. Hence, sexuality educators need to affirm that people of all abilities, are sexual beings (Tepper, 2001).

Teaching sexuality education in school settings is a strenuous and taxing task that requires multifaceted considerations and thorough planning. Teachers are often left with the difficult task of understanding the material, different viewpoints, and sometimes having to select information or follow a curriculum that will meet the needs of all the students. Even if a teacher is not asked to focus on areas of sexuality education, it may be common for teachers to be exposed to a plethora of questions from curious students about the topic, and this may make teachers to feel unsure and uncomfortable about how to handle specific questions. Yet, little is known about the teachers' attitudes about sexuality education or the factors that shape how and what they teach in special needs schools in South Africa.

Given the key role of teachers in disseminating this information, it is imperative to gain an understanding of the teachers' and childcare providers' views, experiences, and beliefs about teaching sexuality, HIV and AIDS education to students in special needs schools. The purpose of the study was to investigate the teachers' and childcare providers' views of sexuality, HIV and AIDS education while working with youth with disabilities at special needs schools in South Africa. The research question was as follows: What are teachers' and other childcare providers' attitudes, beliefs, teaching practices, and levels of knowledge about sexuality and HIV and AIDS education. The life skills curriculum typically included an abstinence based program with topics on human development, self-awareness, self-esteem, decision-making, HIV and AIDS, sexual abuse and the physical aspects of sex.

\section{Method}

\section{Context of the Study}

Teachers in South Africa have been mandated since 1994 to teach sexuality, HIV, and AIDS education to all students as part of the life skills program. Students attending special needs schools in South Africa are typically grouped into five academic phases on the basis of their levels of in- 
tellectual abilities and their need for care: (1) foundation, (2) intermediate, (3) senior, (4) occupational, and (5) school leaver. The schools chosen for the present study provide both basic education and specialized services to students across all types of disabilities as well as to a particular disability type.

\section{Participants}

Altogether 50 special needs schools listed on the Western Cape provincial government website were invited to take part in this study. All 78 participants were employees of the Department of Education working at schools located in four different regions of the province. They taught lessons and or provided services such as counseling and assessment to students with disabilities between the ages of 6 and 20 years old.

\section{Instrumentation}

The Teachers' Views on HIV and AIDS Education Survey was used for the present study. The content of the questionnaire was adapted and modified from two sources: (1) the World Health Organization's interview protocol pertaining to AIDS-related knowledge, attitudes, beliefs, and practices (KABP) (WHO, 1994), and (2) the Human Science Research Council's (a social research institution) South African National HIV Prevalence, Behaviour, and Community Survey (SABSSM II). To ensure its validity and reliability, the instrument was piloted before being used for actual data collection. Six doctoral level graduate students completed the pilot and offered their feedback on how to better improve the content, language, readability, sentence composition, and clarity.

The survey instrument consists of five sections: (1) Demographic characteristics, (2) Knowledge of HIV and AIDS, (3) Attitudes towards HIV and AIDS, (4) Beliefs about HIV and AIDS, and (5) Teaching Practices of HIV and AIDS programs. The construct of Knowledge of HIV and AIDS is operationalized as a cognitive understanding of a fact or commonly expected research or clinical finding. The construct of Attitudes towards HIV and AIDS is defined as a notion to respond in favor or not in favor to an object, person, institution or an event. The construct of Beliefs about HIV and AIDS is operationalized as intentions or behaviors related to attitudes and, therefore, beliefs are primarily determinants of attitudes (WHO, 1994). The construct of Teaching Practices of HIV and AIDS programs is operationalized as methods and techniques used to impart information related to sexuality, HIV and AIDS. Figure 1 displays the ten study variables identified under the four major constructs.

The four major constructs of Teaching Practices, Attitudes, Knowledge, and Beliefs were measured by summing the total scores of the 1,2,3, and 4 study variables, respectively. Each study variable is further comprised of a number of statements to assess a participant's view about certain HIV- and AIDS-related issues or situations. For example, the Knowledge construct was a composite of three

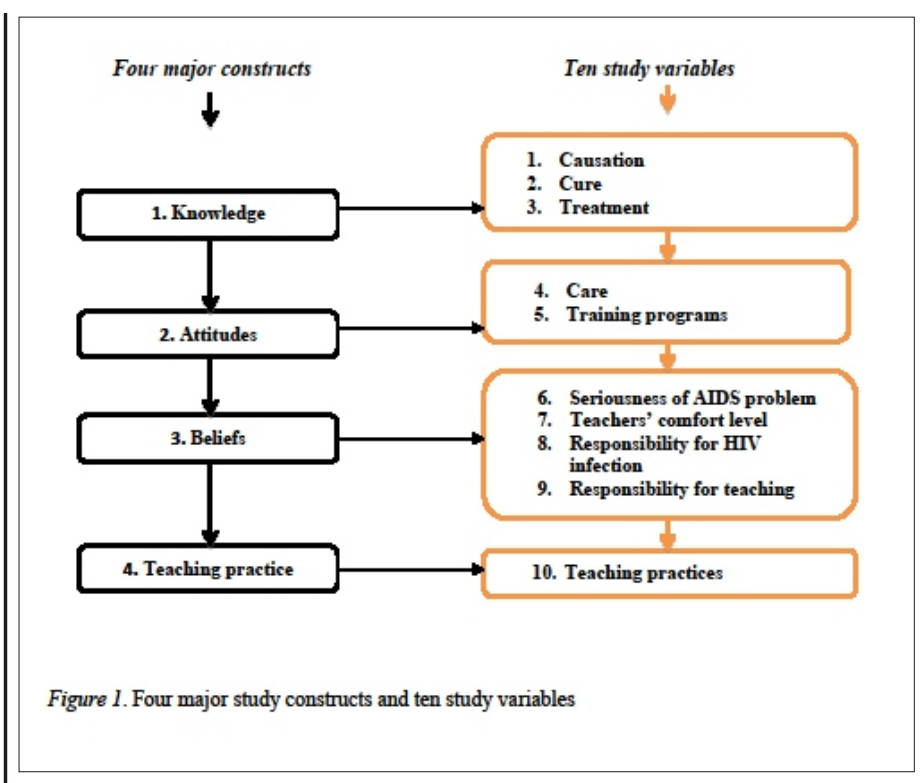

study variables, specifically, Causation, Cure, and Treatment. The Cure study variable contains five statements such as "There is a cure for AIDS." and "HIV infection can be prevented by using condoms." The extent of agreeability with each statement was then measured by using a five-point Likert-type scale, ranging in values from $1=$ Strongly disagree, $2=$ Disagree, $3=$ Neutral, $4=$ Agree, to $5=$ Strongly agree. The demographic information collected included age, sex, language, race, marital status, academic qualification, grade level teaching, and number of years of teaching experience.

\section{Procedure}

Upon the receipt of approval of the research protocol and in compliance with ethical standards from the Institutional Review Board, the first author proceeded to recruit prospective participant schools. Permission was sought from the Department of Education in the Western Cape Province prior to launching the study. The first author then contacted school principals to explain the purpose of the study and the significance of the problem. Briefing sessions were held at some schools by request. Pen-and-paper questionnaires were delivered to schools that agreed to take part, and the first author went back to schools to gather the completed questionnaires. The estimated time to complete the survey was approximately 15 to 20 minutes.

\section{Data Analysis}

The survey data was analyzed using the statistical software package SPSS version 18. Descriptive and inferential statistics provided background information about the participants with regard to their age, sex, race, and years of teaching at the school. Specific descriptive statistics on the 10 study variables and the four major study constructs were generated. To describe the degree of the relationship between the two variables, correlation matrices among the 10 
study variables as well as the four major study constructs were conducted. Responses on individual items for each of the ten study variables were computed into a mean. Thereafter, the ten individual variables were summed to obtain a grand mean for each of the four major constructs.

\section{Results}

\section{Participant Demographic Characteristics}

The 78 participants for the study were 68 teachers and 10 childcare providers working in special needs schools. The majority of the participants were females $(84.6 \%, n=66)$; males comprised only $12.8 \%(n=10)$ of the sample. The average age of the participants was 45.6 years old $(S D=10.9)$ with a range from 21 to 68 . The age categories were as follows: $20-30(11.5 \%, n=9), 31-40$ $(16.7 \%, n=13), 41-50(28.2 \%, n=22), 51-60(32.1 \% n=$ $25)$, and 61 and older $(6.4 \%, n=5)$. Nearly $72 \%(n=56)$ of the participants were married and more than half of the sample $(61.5 \%, n=48)$ spoke Afrikaans. Participant race and ethnicity were based on the system of Apartheid that previously divided South Africans into four categories 'White', 'African', 'Coloured' and 'Indian': $10.3 \%(n=8)$ were African, $33.3 \%(n=26)$ were Coloured, and $55.1 \%(n=43)$ were White. All but one participant had at least three years or more of post-secondary education. This educational qualification includes either a diploma or certificate $(55.1 \%, n=43)$, a bachelor's degree $(19.2 \%, n=15)$, and a postgraduate degree $(21.8 \%, n=17)$. The average number of years of teaching experience for the sample was 13.1 ( $S D$ $=9.7$ ), ranging from 2 months to 38 years. All participants indicated having received a form of training relating to teaching sexuality education for students with disabilities, with the majority of the sample $(69.3 \%, n=54)$ having had a general type of training.

\section{Descriptive Statistics of the 10 Study Variables}

Table 1 depicts descriptive statistics for each study variable, including means, standard deviations, ranges, and alpha levels. The Cronbach alphas for all 10 study variables were less than .70, indicating the internal consistency reliability coefficients for the measures used in the study were slightly low (Creswell, 2009). The variable of causation had the highest overall mean score of 4.5 with a range of scores from 2.60 to 5.00 (i.e., higher scores indicating a higher level of knowledge of the causes of HIV and AIDS), reflective of a high level of knowledge on causes of HIV and AIDS. The second highest mean score was 4.4 for the variable of the teacher's comfort level. This is an indication of teachers who strongly agree about being comfortable talking about HIV and AIDS. The variables of a cure for HIV, the seriousness of HIV and AIDS problems, and teaching practices all had a mean of 4.2 , indicating a high score on each of these items. This indicates a higher level of knowledge of a cure for HIV amongst participants, a high level of agreement of participants taking the problem HIV and AIDS seriously, and lastly, a high level of agreement of participants that the teaching practices related to sexuality, HIV and AIDS are essential. The lowest mean scores were found for the variables of responsibility for teaching HIV and AIDS $(M=3.4)$, care $(M=3.5)$, and responsibility for HIV infection $(M=3.6)$. These lower mean scores indicate the participants' levels of neutrality related to who should be primarily responsible for teaching HIV and AIDS programs, who should be responsible for taking care of the infected, and who should be held responsible for HIV infection.

\section{Correlation Matrix among the 10 Study Variables}

The correlation matrix, as shown in Table 1, depicts statistically significant correlations between the 10

Table 1

\begin{tabular}{|c|c|c|c|c|c|c|c|c|c|c|}
\hline Variable & 1 & 2 & 3 & 4 & 5 & 6 & 7 & $\mathbf{s}$ & 9 & 10 \\
\hline \multicolumn{11}{|c|}{ (18) } \\
\hline 2 & $-48 * *$ & - & & & & & & & & \\
\hline 3 & $-40 * *$ & $.27 *$ & - & & & & & & & \\
\hline 4 & .13 & .17 & $.28 *$ & - & & & & & & \\
\hline 5 & $.31 * *$ & .15 & .15 & .16 & - & & & & & \\
\hline 6 & -.08 & .02 & .11 & .15 & .10 & - & & & & \\
\hline 7 & .10 & $.24 *$ & 20 & .11 & .12 & .11 & - & & & \\
\hline $\mathbf{s}$ & .04 & .11 & .05 & -.09 & .05 & .01 & -.19 & - & & \\
\hline 9 & .18 & $24 *$ & .19 & -.08 & -.08 & .07 & $.29 * *$ & .17 & - & \\
\hline 10 & .14 & $-37 * *$ & .08 & .12 & $-24^{*}$ & $.35 * *$ & $.30 * *$ & -.04 & .09 & - \\
\hline$M$ & 4.5 & 4.2 & 3.8 & 3.5 & 3.8 & 4.2 & 4.4 & 3.6 & 3.4 & 4.2 \\
\hline$S D$ & .43 & .56 & .46 & .71 & .62 & .so & .66 & 50 & .49 & .61 \\
\hline Range & $2.60-5.00$ & $2.40-5.00$ & $2.50-4.60$ & $1.67-5.00$ & $2.00-5.00$ & $2.00-5.00$ & $2.00-5.00$ & $3.00-5.00$ & $1.00-5.00$ & $2.25-5.00$ \\
\hline$\alpha$ & .568 & .541 & .554 & .593 & .575 & .603 & -576 & .632 & .590 & .536 \\
\hline
\end{tabular}


study variables of causation, cure, treatment, care, training, treatment, teachers' comfort level, responsibility for teaching HIV and AIDS as well as HIV infection and teaching practices. Teaching practices shared statistically significant relationships with a number of other variables of interest, but the strongest statistically significant correlations were with cure $(r=.37, p<.01)$ and seriousness about HIV and AIDS $(r=.35, p<.05)$. This finding shows that an understanding of the cure for HIV relates positively to taking the problem of HIV and AIDS seriously. The strongest statistically significant correlation was found amongst cure and causation $(r=.48, p<.01)$, indicating knowledge about HIV and AIDS relates strongly to understanding the cure for HIV and AIDS. A few weaker positive relationships were found for the responsibility of HIV infection with the seriousness of AIDS $(r=.01)$, causation $(r=.04)$, treatment $(r=.05)$, and training $(r=.05)$, but these relationships were not statistically significant. It is important to note that a few negative relationships between variables were found but none of these relationships showed any statistical significance.

\section{Descriptive Statistics of the Four Major Study Constructs}

Table 2 depicts descriptive statistics for each of the four major study constructs, including means, standard deviations, ranges, and alpha levels. The Cronbach alphas for these four major constructs knowledge, attitudes, beliefs and practices were all slightly below .60 , indicating the internal consistency reliability coefficients for the measures used in the study were regarded as somewhat low. The range of scores for the major study construct of knowledge in the present investigation was 2.95 to 4.85 (i.e., higher scores indicating a higher level of knowledge) with an overall mean of 4.2 , indicative of a high level of knowledge

Table 2

Correlation Matrix, Means, Standard Deviations, Ranges, and Alpha Coefficients among the Four Major Study Constructs

\begin{tabular}{lcccc}
\hline & 1 & 2 & 3 & 4 \\
\hline 1. Knowledge & - & & & \\
2. Attitudes & $.41^{* *}$ & - & & \\
3. Beliefs & $.27^{*}$ & .06 & - & \\
4. Teaching Practice & $.24^{*}$ & $.26^{*}$ & $.30^{* *}$ & - \\
$M$ & 4.2 & 3.8 & 3.8 & 4.2 \\
SD & .37 & .49 & .31 & .61 \\
Range & $2.95-4.85$ & $2.00-4.75$ & $3.00-5.00$ & $2.25-5.00$ \\
$a$ & .439 & .486 & .540 & .496 \\
\hline \multirow{2}{*}{$p<.05 .{ }^{* *} p<.01}$. & & & & \\
& & &
\end{tabular}

about HIV and AIDS. The major study construct of teaching practices ranged from 2.25 to 5.00 with a mean score of 4.2 , indicating a high level of agreement amongst participants about the importance of teaching practices of sexuality, HIV and AIDS education. The constructs of attitudes and beliefs both had an average mean score of 3.8 ranging from 2.00 to 4.75 and 3.00 to 5.00 , respectively. First, the mean score for the major study construct of attitudes indicates the participants' levels of neutrality related to taking care of the infected and level of comfort in training programs for all teachers. Second, the mean score for the major study construct beliefs indicates participants' level of neutrality towards taking the problem of HIV and AIDS seriousness, teachers comfort level in terms of teaching HIV and AIDS programs and who should be responsible for teaching HIV and AIDS as well as who should be held responsible for HIV infection.

\section{Correlation Matrix among the 4 Major Study Constructs}

The correlation matrix, as shown in Table 2, depicts statistically significant correlations between all four major constructs of attitudes, knowledge, beliefs, and practices. Positive and statistically significant correlations for teaching practices were found between all other constructs including beliefs $(r=.30, p<.01)$, attitudes $(r=.26, p<.05)$ and knowledge $(r=.24, p<.05)$. The strongest statistically significant correlation was found between knowledge and attitudes $(r=.41, p<.01)$. This indicates that knowledge of HIV and AIDS relates strongly to an individual's attitudes towards HIV and AIDS. A weak positive relationship was found between beliefs and attitudes $(r=.06)$; this relationship, however, was not statistically significant.

The present study also examined the level of seriousness of HIV and AIDS under the construct of beliefs. Participants were asked to select from a list the three factors that most influenced them to take the problem of HIV and AIDS seriously. The factors with the highest percentages and with the most influence were reading articles $(67.9 \%, n$ $=53)$, learning HIV and AIDS statistics $(43.6 \%, n=34)$, knowing someone with HIV and AIDS $(43.6 \%, n=34)$, listening to radio and television $(39.7 \%, n=31)$, and speaking to someone with HIV and AIDS $(38.5 \%, n=30)$. The factors with the least influence on participants regarding the level of seriousness about HIV and AIDS were signs and billboards $(3.8 \%, n=3)$, voluntary counseling and treatment $(5.1 \%, n=4)$, and talking to friends $(9.0 \%, n=7)$. Only $3.8 \%(n=3)$ of participants indicated that they were not concerned at all about the level of seriousness of HIV and AIDS.

\section{Discussion}

The purpose of this study was to investigate the teachers' and childcare providers' views related to teaching sexuality, HIV and AIDS programs to students with disabilities. The present study yielded a number of high overall 
mean scores for the study variables. The highest overall mean scores were for the variables of the causation of HIV and AIDS, the teachers' comfort levels, the seriousness of HIV and AIDS, and teaching practices of sexuality and HIV and AIDS. Given the high levels of educational qualification of this sample, it is not surprising that they scored high on the variable of causation. Therefore, the findings indicate that participants are very knowledgeable about what causes HIV and AIDS, issues related to the cure for HIV and AIDS and the treatment methods for individuals infected with HIV and AIDS. According to Mulindwa (2003), educational level is strongly associated with one's knowledge of, familiarity with, and perceptions of a particular topic.

Focusing on the topic of sexuality education, however, Romeo and Kelley (2009) warn that sexuality education is often reduced to biological and or value-based approaches, disregarding the essence of relationship building, developing feelings, and practicing appropriate social and sexual behavior (NICHCY, 1992). James et al., (2006) in their study confirmed this notion with teachers reporting more comfort with teaching a more fact-based rather than skill-based curriculum. This may explain the present study's findings of a high mean in the teachers' levels of comfort and the high mean score related to teaching practices, which include the teachers' and childcare providers' willingness and open-mindedness to teach sexuality, HIV and AIDS programs to students with disabilities as well as to those students who are HIV infected. Even though these present findings about high levels of comfort in teaching sexuality education are similar to Ninomyia's (2010) study focusing on teachers' experiences, the coverage of topics in sexuality education, and comfort levels, and views about professional practice, more in-depth explorative studies are needed to unravel whether these programs are indeed taught as a fact-based topic. The high mean score on the teachers' comfort levels further relates to teachers indicating their level of comfort in talking to family members, colleagues, and students with disabilities about sexuality, HIV and AIDS. It is very encouraging that teachers are invested and show commitment to engaging with the topic of sexuality given that this topic is often viewed to be a taboo subject in many cultures (Diller, 2011). The sociocultural elements which influence how sexuality is viewed and contribute to the rapid spread of the disease include male dominated gender inequality, sexual violence, stigma and discrimination.

As the present findings further indicate, it is evident that participants do take the problem of HIV and AIDS very seriously. The high mean score on the seriousness of HIV and AIDS variable also strongly relates to the factors that participants indicated most influenced them to take this problem seriously. Participants pointed out that these factors include reading specific articles about this topic, learning HIV and AIDS statistics, and knowing someone with HIV and AIDS. This may reflect the high number of people living with HIV in South Africa. The findings also indicate a strong association between the participants' knowledge of
HIV and AIDS and the cure for HIV and AIDS, indicative of their level of seriousness in taking action to keep informed through reading articles, checking information on HIV statistics, participating in workshops, and engaging with someone they know who is infected with HIV. In addition, the four major study constructs provide additional descriptions and understandings about the participants' views related to teaching sexuality, HIV and AIDS programs to students with disabilities. The constructs of both knowledge and teaching practices had high mean scores while the remaining two constructs of attitudes and beliefs had moderately average mean scores. The construct of attitudes relates to how comfortable teachers are towards training programs provided to only those teachers who are assigned to teach this topic. This moderately low mean score may be an indication that teachers are in doubt about providing training only to select staff members. The construct of belief relates to teachers' perception of who should be responsible for teaching HIV and AIDS programs to students with disabilities. Thus, they may feel that the responsibility for teaching these programs lies not only with them, as educators identified to teach this subject, but it also includes the remaining staff members, parents, and the government.

\section{Limitations of the Study}

The current study has a number of limitations. Sampling procedure, sample size, response rate, participant bias, representativeness, and measurement reliability and validity may have affected the research outcomes. The convenience sample was selected from the names of special needs schools that appeared on the website of the Department of Education. Teachers working at non-listed academies, therefore, were inadvertently excluded from the pool of prospective participants. Because all the participants worked in Western Cape Province and due to varying factors such as demographic characteristics, the availability of resources, and teaching experience (Leedy \& Ormrod, 2005), the findings cannot be generalised to all provinces of South Africa. For instance, the majority of participants in this study were older White Afrikaans-speaking female teachers. Moreover, the teachers in the said province face fewer challenges and difficulties than their teaching counterparts in other provinces because it is one of the most resourceful and wealthiest provinces in the country. Western Cape Province schools are known to receive various educational and health related interventions both from local and international agencies for the purpose of research.

Another drawback of the study is the small sample size. Despite a concerted effort coordinated by the research team to recruit prospective participants and waves of reminder emails and follow-up phone calls, only 78 teachers took part (a response rate of 22\%). Therefore, the data in the present study may not accurately reflect the attitudes, knowledge and beliefs of a more complete and representative sample of teachers and childcare providers. Additionally, the size of the sample was also likely a factor in the lack of overall significant findings. As with any survey research, an inherent weakness is data's heavy reliance on the 
participants' self-report responses, the accuracy of which is often quite difficult to estimate. Lastly, the Cronbach's alpha coefficients of the scales used in the study to assess the major constructs and all the predictor variables were slightly below .60, indicating that the instruments may need further development.

\section{Implications for Special Needs Schools}

On the basis of the findings of this small scale investigation, there seem to be a number of implications worth noting for special needs schools. Even though it is encouraging to observe that participants were generally very comfortable talking about and teaching sexuality, HIV and AIDS programs to students with disabilities, it maybe that this level of comfort are attributed to their teaching sexuality as a fact-based subject rather than addressing more sensitive, relationship building and more importantly, HIV risk factors. This is important given the high incidence and prevalence rates of HIV in the country (Statistics South Africa (2013) and children with disabilities most often missed in prevention programs. If this is the case, the danger may be that teachers and childcare providers may underestimate the risk factors if students with disabilities are viewed as asexual or not ready to hear the information (Di Giulio, 2003; Murphy \& O'Callaghan, 2004). The failure of AIDS advocacy groups to recognize that students with disabilities are at equal risk of HIV infection as students without disabilities can lead to disastrous consequences (Chapell \& Radebe, 2009). It is thus worrisome that many special education teachers either impart little or no information about sexually risky behaviors (Lamorey \& Leigh, 1996). As a result students with disabilities, devoid of proper forums to acquire correct knowledge on reproductive issues and safe sex practices in school settings, often turn to mass media or their peers as the main sources of information,(Blanchett, 2000). Hence, special education teachers play an indispensable role in protecting the sexual health of their students with disabilities, who are otherwise more vulnerable to sexual abuse and uncanny exploitations.

Although close to $70 \%$ of the current sample had received general training on sexuality education, their belief about teaching programs pertaining to HIV and AIDS was moderately low. This may reveal that the quality of training materials need to be updated to include ongoing and relevant topics, a specific focus on pedagogy, and how to work with students with disabilities. In order to better suit the unique needs of their students, teachers at special needs schools are advised to modify and revamp the standard training materials designed with mainstream schools in mind. Blanchett and Wolfe (2002) caution sexuality educators to guard against imposing their own personal values when transmitting messages to information seekers with disabilities. The boundary between choosing appropriate materials for the class and imposing one's own values when modifying them is vague and indistinguishable. Thus, this is an awareness that should be highlighted continuously as teachers develop the best teaching strategies and approaches to teaching sexuality education.
To make the matter more complicated, not all instructors involved in teaching sexuality education receive training first-hand or in person. In some cases a more senior staff member will be selected, who then has to share the training material with the rest of the staff. In order to overcome this inefficiency, it would be advisable to implement online training for all teaching staff members. Online workshops have been found to favorably improve the teachers' knowledge, attitudes, and self-efficacy beliefs toward sexuality education and intellectual disabilities (Gonzalez-Acquaro, 2009). Given that most schools in South Africa now have updated computer facilities and internet access for all teaching staff, this form of virtual instruction may prove to be a very beneficial tool to enhance the quality of training. Important to note though is to first provide teachers with strategies to deal with their own personal biases, beliefs and attitudes about sexuality so they are aware of how this may have an impact on their teaching related to sexuality, HIV and AIDS to their learners. Even though the Department of Education is responsible for the curriculum, an ad hoc committee can develop guidelines for how to adapt the supportive material used to teach sexuality education at individual schools. However, much work is needed at individual school level around social inclusion, visibility and accepting people with disabilities as active human beings in society.

The association between knowledge and attitudes evidenced by the data is an illustration of the vital relationship between relevant and accurate information and the teachers' outlook and stance about teaching the topic of sexuality education. The high mean scores reported on both these study constructs could serve as an impetus for the Department of Education to invest in more current and updated training efforts for all teaching staff members. Decisions on the type of sexuality education programs, curriculum, and standards that should or should not be provided in schools are often left to the local provincial level. Typically, the contents include abstinence based, abstinence only, abstinence only until marriage, and fear based programs (Gonzalez-Acquaro, 2009). There appears to be no specific focus on disability given that programs are based on the needs of students in mainstream schools and not on the needs of students in special needs schools. Moreover, many of these types of programs are often developed to add to or expand on the information that students presumably receive at home from their parents (SIECUS, 2001). Based on the responses of the participants, they feel their students obtain information on this topic primarily at school and on a limited basis from parents at home. Collaboration between the parents of students with disabilities, community leaders, and members from disability advocacy groups should be considered as a strategy and a way forward to develop sexuality programs that incorporate a focus on disability. As an entry point, parents can be invited to discuss the curriculum during their parenting evenings at school where they can also be provided with the necessary training needed to educate and empower them to support their children. 
A noteworthy contribution made by the new South African democratic government was to introduce HIV and AIDS education in all public schools. Although the national government's policy to eradicate the HIV and AIDS epidemic has been inconsistent due to changes in the administration, its effort to implement mandatory life skills, and HIV and AIDS education is instrumental in attaining the desired outcomes (Mangani et al., 2005). Consequently, the foundation of the curriculum was built on the classic cognitive and social learning theoretical frameworks that contributed to new knowledge gained by students on this topic. But the literature indicates that a significant number of students with disabilities have been left out of formal education opportunities (Schneider, 2000; Watermeyer et al., 2007). As such, the role of teachers becomes more cumbersome and challenging, and they need help and guidance on how to effectively assist and deal with students with disabilities given their lack of inclusion in educational opportunities related to HIV and AIDS.

\section{Suggestions for Future Research and Practice}

The responses of the participants point out implications for future research as well as practice. In SA, issues related to disability is addressed at national level within the office of the President with both the OSDP and INDS striving to attain full inclusion and integration of the needs and participation of the disabled in all government departments. Yet, there is limited empirical data regarding how the implementation process is monitored and more importantly its success in making a difference in the lives of people with disabilities. More studies are recommended in order to better understand the impact of policymaking related to the integration of people with disabilities into society.

The present study highlights the urgent need for measures that will keep track of accountability for disability in all special needs schools, specifically related to sexuality, HIV and AIDS education. This is reflected in the frustration and concerns of the participants about sexuality, HIV and AIDS programs not being tailored to the needs of their students with various kinds of disabilities. In addition, a pro-active approach should be adopted in which teachers, parents, advocates, rehabilitation professional and community support groups who know or work with students with cognitive, intellectual, and developmental disabilities can provide essential education about sex, relationships and appropriate sexual expression (Sweeney, 2007).

Another suggestion for future practice is to redesign and introduce new educational materials that are explicitly tailored to accommodate the needs of youth with disabilities instead of teachers having to adapt and modify programs developed for mainstream schools. Furthermore, training programs are encouraged to take into consideration the valuable input from teachers and childcare providers at special needs schools and include topics on how to be at ease and comfortable with their own sexuality; information, education and communication related to how to effectively teach students with disabilities; and the increased sensitivity of parents and/or guardians, family members and the en- tire community about the plight of students with disabilities, in order to curtail stigma and discrimination.

Recommendations for future research should include participatory action research that involves collaborating with parents, disability activists and the community as a way of helping to create awareness about the development of a positive sexuality for all students with disabilities. Participatory action research focuses on effecting change within individuals, as well as the communities and cultures to which they belong (McTaggart, 1991). Therefore, researchers should work closely with the Department of Education as they are the main stakeholders for creating opportunities for collaboration as well as impacting how students receive information related to sexuality, HIV and AIDS. It is imperative to build and maintain good working alliances with teachers and childcare providers so that conducting high quality research and enhancing its outcomes are feasible.

While the present investigation sheds light on the views of teachers and childcare providers about teaching sexuality, HIV and AIDS to students with disabilities, the study was conducted in just one of the nine provinces of South Africa. Scaffolding on the thriving momentum of the current study, research projects of a similar nature can be replicated in other parts of the nation. Replication research within more provinces would enormously expand the parameters of generalizability and help control for the role of potential confounding variables.

\section{References}

Blanchett, W. J. (2000). Sexual risk behaviours of young adults with LD and the need for HIV/AIDS education. Remedial and Special Education, 21(6), 336-345.

Blanchett, W. J., \& Wolfe, P. S. (2002). A review of sexuality education curricula: Meeting the sexuality education needs of individuals with moderate and severe intellectual disabilities. Research and Practice for Persons with Severe Disabilities, 27(1), 43-57.

Chappell, P., \& Radebe, N. (2009). HIV \& AIDS and youth with disabilities: A baseline study of youth with disabilities living in uMgungundlovu District, KwaZulu Natal. CREATE.

Cheng, M. M., \& Udry, M. J. (2002). Sexual behaviors of physically disabled adolescents in the United States. Journal of Adolescent Health, 31(1), 48-58.

Creswell, J. W. (2009). Research design: Qualitative, quantitative, and mixed method approaches (2nd ed.). Thousand Oaks, CA: Sage Publications.

Department of Education (2004). Education White Paper 6: Special needs education. Building an inclusive education and training system. Pretoria, South Africa: Department of Education.

Di Giulio, G. (2003). Sexuality and people living with physical or developmental disabilities: A review of key issues. Canadian Journal of Human Sexuality, 12(1) 53- 68.

Diller, J. V. (2011). Cultural diversity: A primer for the humans services (4th ed.). Belmont, CA: Brooks/Cole.

Greenberg, J. S. (1989). Preparing teachers for sexuality education. Theory in Practice, 28(3), 227-232.

Groce, N. E. (2003). HIV/AIDS and people with disability. Lancet, 361(9367), 1401-1402.

Groce, N. E. (2005). HIV/AIDS and individuals with disability. Health and Human Rights, 8(2), 215-224.

Groce, N. E., Yousafzai, A., Dlamini, P., \& Wirz, S. (2006). HIV/AIDS and disability: A pilot survey of HIV/AIDS knowledge among 
a deaf population in Swaziland. International Journal of Rehabilitation Research, 29(4), 319-324.

Gonzalez-Acquaro, K. (2009). Teacher training, sexuality education, and intellectual disabilities: An online workshop. Current Issues in Education, 11(9). Available: http://cie.ed.asu.edu/volume11/number9/

James, S., Reddy, P., Ruiter, R. A. C., McCauley, A., \& Van den Borne, B. (2006). The impact of an HIV and AIDS life skills program on secondary school students in Kwazulu-Natal, South Africa. AIDS Education and Prevention, 18(4), 281-294.

Kaiser Family Foundation (2007). HIV/AIDS policy fact sheet. Washington, DC.

Lamorey, S., \& Leigh, J. (1996). Contemporary issues education: Teacher perspectives of the needs of students with disabilities. Remedial and Special Education, 17(2), 119-127.

Leedy, P. D., \& Ormrod, J. E. (2005). Practical research: Planning and design (8th ed.). Upper Saddle River, NJ: Pearson.

Louw, J. S. (2001). Exploring teachers' perceptions and views of childhood sexuality in primary schools in South Africa. Unpublished master thesis, University of the Western Cape, Cape Town, South Africa.

Magnani, R., MacIntyre, K., Karim, A. M., Brown, L., Hutchinson, P., Kaufman, C., Rutenburg, N., Hallman, K., May, J., \& Dallimore, A. (2005). The impact of life skills education on adolescent sexual risk behaviors in KwaZulu-Natal, South Africa. Journal of Adolescent Health, 36(4), 289-304. doi: 10.1016/j.jadohealth.2004.02.025

McCary, J. (1982). Human sexuality. Belmont, CA: Wadsworth.

McTaggart, R. (1991). Principles for participatory action research. Adult Education Quarterly, 41(3), 168-187.

Mpofu, E., Jelsma, J., Maart, S., Levers, L. L., Montsi, M. M. R., Tlabiwe, P., Mupawose, A., Mwamwenda, T., Ngoma, M. S., $\&$ Tchombe, T. M. S. (2007). Rehabilitation in seven sub-Saharan African countries: Personnel education and training. Rehabilitation Education, 21(4), 223-230.

Mulindwa, I. N. (2003). Study on reproductive health and HIV/AIDS among persons with disabilities in Kampala, Katakwi and Rakai Districts. Disabled Women's Network and Resource Organization (DWNRO) with Support from Action Aid Uganda: Kampala, Uganda.

Murphy, G. H., \& O'Callaghan, A. (2004). Capacity of adults with intellectual disabilities to consent to sexual relationships. Psychological Medicine, 34(7), 1347-1357.

Nation Information Center for Children and Youth with Disabilities (NICHCY) (1992), Sexuality education for children and youth with disabilities, 1(3), 1-27. Washington, DC.

Ninomyia, M. M. (2010). Sexual health education in Newfoundland and Labrador schools: Junior high school teachers' experiences, coverage of topics, comfort levels and views about professional practice. Canadian Journal of Human Sexuality, $19(1 \& 2), 15-26$

Romeo, K. E., \& Kelley, M. A. (2009). Incorporating human sexuality content into a positive youth development framework: Implications for community prevention. Children and Youth Services Review, 31(9), 1001-1009. doi: 10.1016/j. childyouth.2009.04.015

Schneider, M. (2000). One in twenty: Youth and disability: Selected findings from the national baseline survey. Development $U p$ date, 3, 56-67.

Schultz, J. B., \& Boyd, J. R. (1984). Sexuality attitudes of secondary teachers. Family Relations, 33(4), 537-541.

Sexuality Education and Information Council of the United States SIECUS (2001). Issues and answers: Fact sheet on sexuality education. SIECUS Report Supplement, 29(6), 1-8.
Statistics South Africa. (2013). Mid-year population estimates 2013. Pretoria, South Africa: Stats.

Sweeney, L. (2007). The importance of human sexuality education for students with disabilities. The Exceptional Parent, 37(9), 36-39.

Tepper, M. (2001). Becoming sexually able: Education to help youth with disabilities. SIECUS Report, 29(3), 5-13.

Thomas, L. L., Long, S. E., Whitten, K., Hamilton, B., Fraser, J., \& Askins, R. V. (1985). High school students' long-term retention of sex education information. Journal of School Health, 55(7), 274-278.

UNAIDS. (2008). Report on the global AIDS epidemic: Executive summary. UNAIDS.

UNAIDS. (2009). Report on the global AIDS epidemic: Executive summary. UNAIDS.

UNICEF. (2013). The state of the world's children: Children with disabilities. UNICEF.

Watermeyer, B., Swartz, L., Lorenzo, T., Schneider, M., \& Priestley, M. (2007). Disability and social change: A South African agenda. Pretoria, South Africa: Human Sciences Research Council.

Wazakili, M., Mpofu, R. \& Devlieger, P. (2009). Should issues of sexuality and HIV and AIDS be a rehabilitation concern? The voices of young South Africans with physical disabilities. Disability and Rehabilitation, 31(1) 32-41. doi: 10.1080/ 09638280802280619

World Bank (2004). Disability and HIV/AIDS. Retrieved from http://web.worldbank.org/WBSITE/EXTERNAL/TOPICS/E XTHEALTHNUTRITIONANDPOPULATION/EXTPHAA G/0,,contentMDK:20655822 menuPK:1314766 pagePK:64 229817 piPK:64229743 theSitePK:672263,00.html

World Bank (2008). HIV/AIDS and Disability Global Survey. Retrieved from ttp://cira.med.yale.edu/globalsurvey/

World Health Organization (1994). Interview schedule on knowledge, attitude, beliefs and practices. Global Progamme on AIDS. Social and Behavioural Research Unit.

Yarber, W. L., \& McCabe, G. P. (1984). Importance of sex education topics: Correlates with teacher characteristics and inclusion of topics in instruction. Health Education, 15(1), 36-41.

Julia S Louw, PhD, Senior Research Specialist, Human Sciences Research Council, HIVIAIDS, STIs \& TB (HAST) Research Programs, Durban 4001, South Africa

John Kosciulek, PhD, Professor, Michigan State University, Department Counseling, Education Psychology \& Special Education, East Lansing, MI, 48824

Roy Chen, PhD, Associate Professor, The University of Texas-Pan American, USA, Department of Rehabilitation, Edinburg, Texas 78539

Correspondence regarding this article should be addressed to Julia S. Louw, PhD, Human Sciences Research Council, HIV/AIDS, STIs \& TB (HAST) Research Programs, 750 Francois Road, Cato Manor, Durban 4001, South Africa (Email: jslouw@hsrc.ac.za). 
Reproduced with permission of the copyright owner. Further reproduction prohibited without permission. 